Original Article

\title{
CONCEPT MAPPING - AN EFFECTIVE TOOL TO PROMOTE CRITICAL THINKING SKILLS AMONG NURSES
}

\author{
T. Nirmala ${ }^{1} \&$ B. S. Shakuntala ${ }^{2}$ \\ ${ }^{1}$ Vice Principal, PSG College of Nursing, Coimbatore, Tamilnadu \& \\ ${ }^{2}$ B.S. Shakuntala, Former Dean, AECS M aruthi College of Nursing, Bangalore, Karnataka, India. \\ Correspondence: \\ T. Nirmala, \\ E-mail : nirmala_cbe@yahoo.com
}

\section{Abstract :}

Title : Effect of Concept M apping in Development of Critical thinking (CT) Skills among B. Sc Nursing Students

Objectives : To evaluate the effectiveness of concept mapping as a teaching strategy to develop critical thinking skills. Materials and Methods : Pretest, post test control group design was used. The IV year B.Sc nursing students were included as experimental group $(n=40)$ and control group $(n=44)$. The experimental group was given a training to prepare nursing care plans using concept mapping. The training programme was for 12 weeks where the participants were given case study scenarios every week to prepare nursing care plans using concept map. The experimental group and control group were again assessed for the critical thinking skills. The concept maps were evaluated using scoring criteria.

Results: In the post test, there was a significant difference in the critical thinking scores of both the groups at 0.05 level. ( $t=2.16)$. A significant improvement was identified between the pretest and post test critical thinking scores of experiment group at 0.05 level $(t=2.0)$. Comparison of concept mapping scores of the experimental group in the pretest and post test showed a highly significant difference at 0.041 level.

Conclusion: The study was able to show a significant improvement in the critical thinking skills of nursing students. However, the critical thinking scores were poor due to the high standard of the assessment tool. It is needed to develop critical thinking skill assessment tool which will suit the nursing community and further research is required to promote concept mapping as a teaching and learning strategy.

Keywords: Concept M apping, Critical thinking, nursing process

\section{Introduction:}

Critical thinking (CT) is currently a highly valued educational outcome throughout the educational spectrum, especially in relation to higher and professional education. Nursing education worldwide is also embracing the construct critical thinking as a desirable educational outcome and realizes the importance of eliciting the evidence of critical thinking in nurse's reasoning process. ${ }^{(1)}$

Recent trends in nursing education have led the nursing educators to promote meaningful learning among the novice nurses. ${ }^{(2)}$ The new nurse graduates have to think critically and solve problems in a variety of clinical settings ${ }^{(3)}$.

The present nurse educators feel that the nursing care plans done by the students are not case sensitive and need in-depth comprehension of client's physical, psychological, social and spiritual health. It is felt by the student nurses that writing nursing care plans is tiring and time consuming effort. The lacunae in the objective evaluation of traditional care plans demands the nursing educators to research for an appropriate solution which will solve this complex problem of presenting and evaluating the nursing care plans more objectively. One of the best solutions for this problem is the promotion of meaningful learning through the usage of concept maps. In addition, the concept mapping is recognized as a teaching strategy that promotes critical thinking because it stimulates deep understanding among the learners. ${ }^{(4,5)}$ However, the concept mapping hasn't gained its due attention from the nurse educators.

In view of this, the present study aims to evaluate the effectiveness of concept mapping in promotion of critical thinking skills in nurses.

Critical Thinking and Concept Mapping: It is understood 
that critical thinking is purposeful, self-regulatory judgment which results in interpretation, analysis, evaluation, and inference, as well as explanation upon which the judgment is based. ${ }^{(6)}$ Few definitions of critical thinking defines it as reasonable, reflective thinking focused on what to believe or do, the propensity to engage in an activity with reflective skepticism, purposeful goal directed thinking, the art of thinking about thinking while thinking to make thinking better, purposeful and with selfregulatoryjudgment. ${ }^{(7)}$

In nursing, critical thinking is the ability to think in a systematic and logical manner with openness to question and reflect on the reasoning process which is used to ensure safe nursing practice and quality care. Critical thinking when developed in the practitioner includes adherence to intellectual standards, proficiency in using reasoning, a commitment to develop and maintain intellectual traits of the mind and habits of thought and the competent use of thinking skills which will develop the abilities for sound clinical judgments and safe decisionmaking. ${ }^{(8)}$

The primary goal of nursing education is to assist nurses and nursing students learn how to synthesize information, think critically, and use clinical evidence appropriately. Guiding students in these complex mental processes requires nurse educators to choose learning activities that move beyond teaching facts and their application to prompting advanced critical thinking and clinical decision making. Teaching nurses to think critically and use evidence is a challenge because it requires educators to "see" the learners' thinking. ${ }^{(9)}$

Concept mapping is a technique developed by Joseph $\mathrm{D}$ Novak in 1970s for visualizing the relationships among different concepts. ${ }^{\left({ }^{(1)}\right)}$ The concept mapping is said to result in meaningful learning ${ }^{(11)}$ and has been utilized for over 25 years as a valuable tool for meaningful learning in educational settings. ${ }^{(12)}$

The components of concept maps include meaningful prepositions, connecting words, cross links and relevant examples. ${ }^{(13,14)}$ Among them, the cross links are responsible and an evidence for the development of critical thinking or meaningful learning which connects different vertical linkages in the conceptual structure. ${ }^{(15)}$ The prepositions can be rote learned whereas the cross links relate concepts in different domains that promote the non - linear or lateral thinking which is an essential quality of critical thinking.

Many Healthcare Educators have recently adapted it as a useful instructional aid to promote critical thinking and prepare students for clinical practical experience. The concept map assists students to correlate client's diagnoses, symptoms, treatments, and interventions and then problem solve in clinical decision-making. A quasiexperimental study evaluated the effectiveness of developing critical thinking skills in baccalaureate nursing students using concept mapping as a teaching strategy and the experimental group scores improved significantly $(p<$ $.05)$ on an overall score and on analysis and evaluation scales. ${ }^{(12)}$

A meta-analysis of the research studies with regard to concept mapping demonstrates that this teachinglearning method assists nurse educators to prepare graduates to think critically in the complex health care environment. $^{(2)}$

Another study done in northeast Florida hospital found a higher post concept map scores among the GNM students $(n=14)$ attending an orientation program. ${ }^{(16)}$ The same result was replicated in another study with 28 associate degree nursing students. ${ }^{(17)} \mathrm{A}$ group of doctoral nursing students expressed that while concept mapping, they liked the problem solving and interactive nature of the activity, logical reasoning for their decisions, deeper understanding of the content and above all there is no one correct solution to concept mapping. ${ }^{(3)}$ An online course on 'distance education to adults' for the nursing used the concept mapping and reflective journal to assess the thinking process of the students and found that they helped the students to self assess their own thinking processes. ${ }^{(18)}$

The maps foster a long term change in thinking and contribute to changing adult students' learning strategies. 
Sixty five percent of the students who participated in research by doing concept mapping in the first semester continued to use it in the next semester too. ${ }^{(19)} \mathrm{A}$ quasiexperimental study done in $\mathrm{M}$ angalore city of India found that there was a significant improvement in the concept map score in a short-term training for one week (personal communication)

\section{Methodology:}

A type of quasi-experimental study, pretest post test control group design was used in this study. The final year B.Sc. nursing students from two different college of nursing were selected as experimental $(n=40)$ and control group $(n=44)$. (Fig 1) During the final year, the nursing students undergo intensive training in midwifery for one year along with other subjects. This study included the case scenarios from midwifery.

After obtaining the approval from the Institutional review board (IRB), both the groups were given a standard tool called 'thinking skill assessment tool' from Cambridge University to identify their critical thinking level. The tool contained 32 multiple choice questions involving all the critical thinking skills. Following the pre-assessment, the experimental group was given an introductory lecture on Concept mapping and its applicability in nursing process as the participants were not familiar with the use of concept mapping.

After the lecture, the students in the experimental group were divided into eight small groups of five. The groups were given the first case study scenario from midwifery and asked to make a concept map under the non-participatory observation of the researcher. The eight concept maps were evaluated using the scoring criteria as suggested by Novak and Godwin as each meaningful preposition = 1score, Hierarchy $=5$ scores, Examples $=1$ score, and cross links $=10$ scores. The concept maps were evaluated by two raters and inter rater reliability was determined using Kappa method. It was found almost perfect. (Prepositions = 0.738 , Hierarchy $=0.875$, Examples $=1.0$, Cross links $=1.0$ )

From the second week, the experimental group was given case study scenarios every week and asked to make concept map for the next 10 weeks. The group met three days in a week for one hour. The group members were designated as moderator, recorder, reporter, time keeper and evaluator. The role is exchanged every week to ensure the participation of each student. During the first day, the students discussed and referred to the literature to learn and clarify the concepts in relation to the given case scenarios. On the second day, the students were asked to make the concept map and on the third day, each group shared their concept map with other groups. During the discussion, the researcher encouraged the participants indentify the individuality and differences in each concept maps which helped the students in further sessions.

On the 12 week, the students were given the same first case study scenario to do the concept map and were evaluated for post test. Finally, the experimental group and control group were again assessed for the critical thinking skillsusing the same tool.

\section{Results and Discussion:}

The analysis of pretest scores of critical thinking skills among both the groups revealed that the mean $\&$ STD of critical thinking scores of experimental and control group as $7.25,7.9$ and $2.8,2.9$ respectively. The pretest scores of experimental group ranged from 1 to 13 and control group from 3 to 14.

The mean and STD of post test critical thinking scores among the experimental and control group was found to be $8.2,3.0$ and 7.7, 2.76 respectively. The post test scores ranged between 2 to 16 in the experimental group and 3 to 14 in the control group.

The comparison between the pretest and posttest CT scores of control group by Paired 't' test showed that there was no significant difference between two which determined that there was no change in the critical thinking skills of the participants in the control group. $(t=$ 0.661) (Fig 2)

The comparison of post test critical thinking scores of experimental and control groups showed that there was a significant improvement in the critical thinking scores 


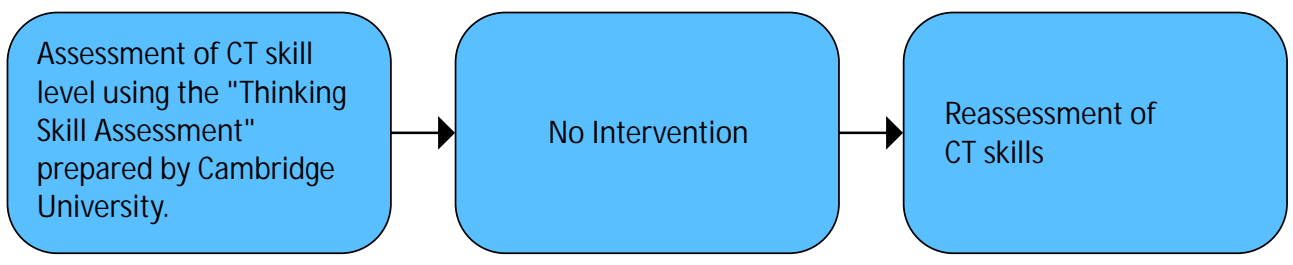

Control group ( $n=44)$

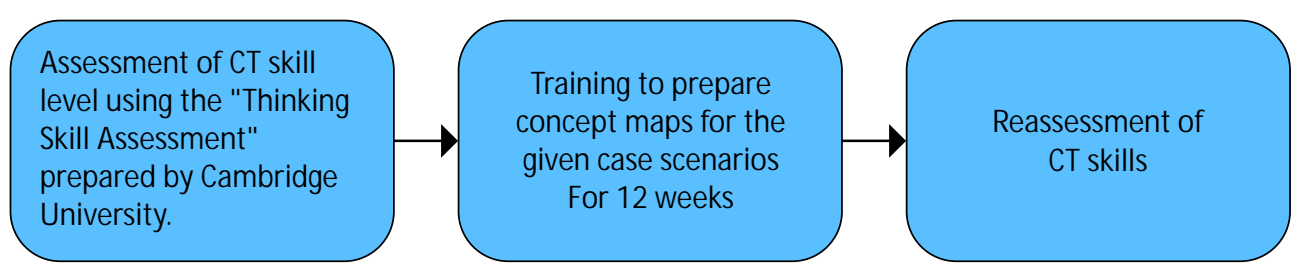

Experimental group

$(n=44)$

Figure 1: Pretest Post test Control group design

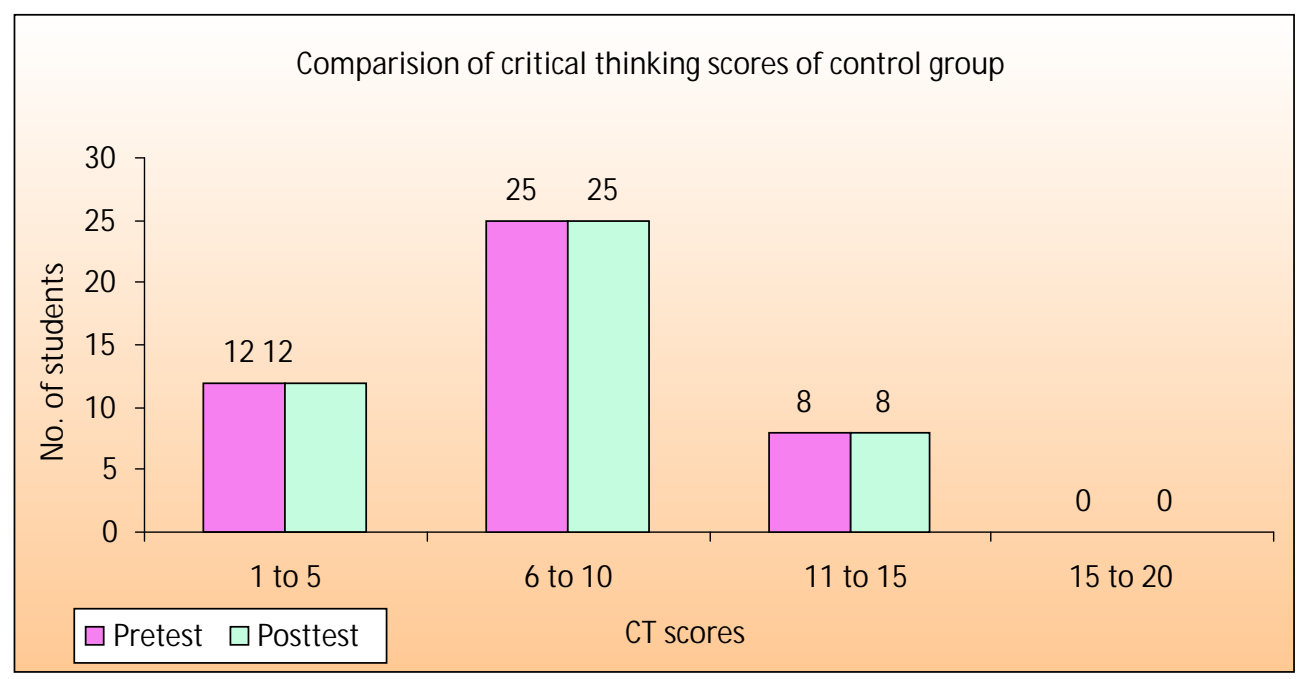

Figure 2 : Pre and post critical thinking scores of control group

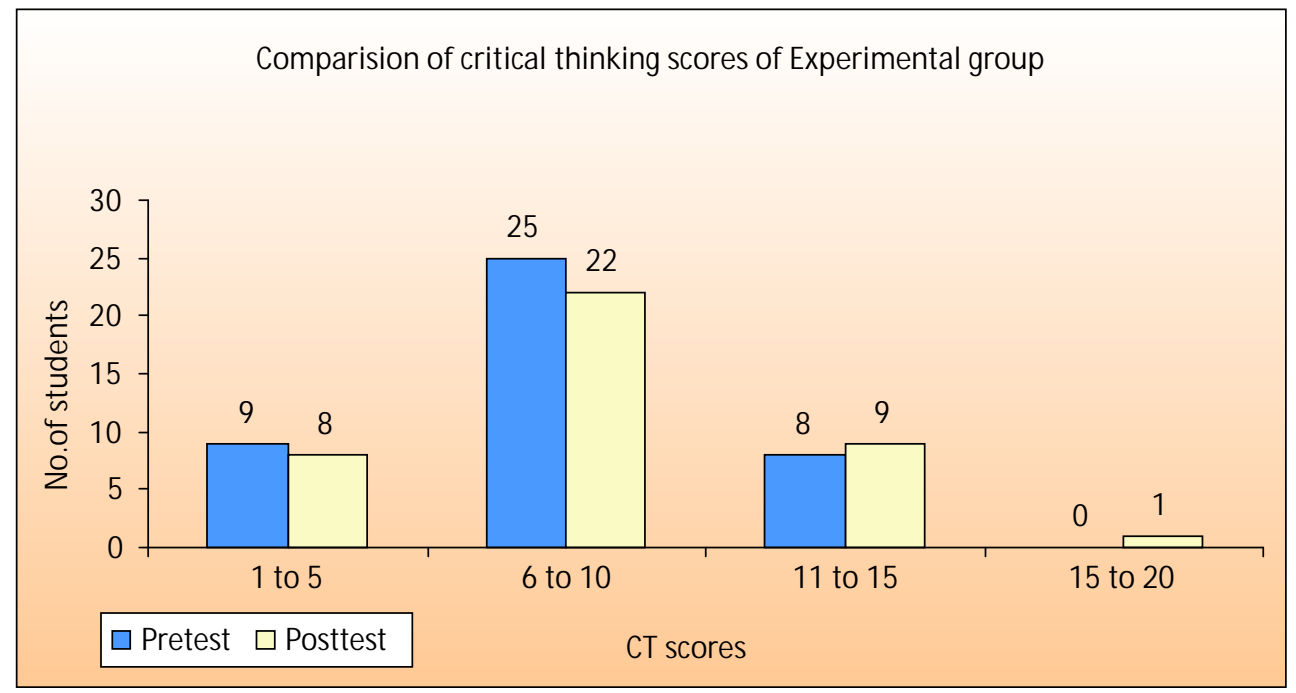

Figure 3 : Pre and post test critical thinking scores of Experimental group 


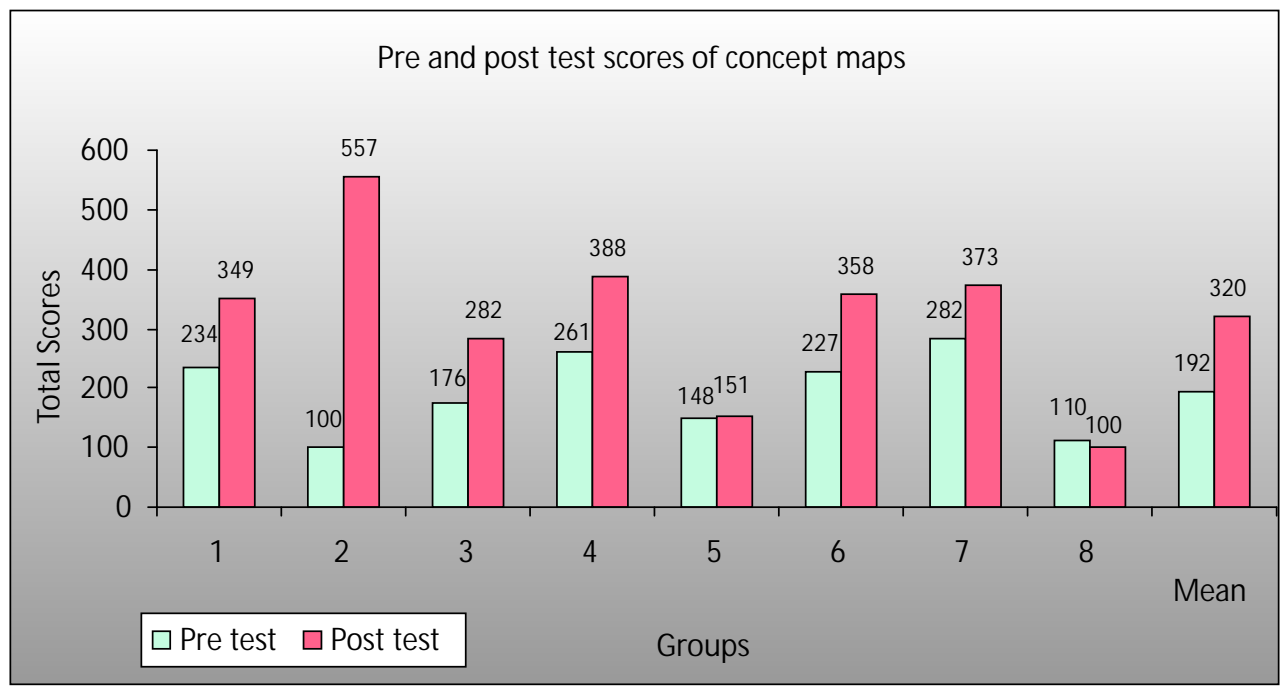

Figure 4 : Pre and post concept map scores of Experimental group

Table 1 Critical Thinking scores before and after the training programme

\begin{tabular}{|c|c|c|c|c|c|c|}
\hline \multirow[t]{2}{*}{ S.No } & \multirow[t]{2}{*}{ Group } & \multicolumn{2}{|c|}{ Pretest } & \multicolumn{2}{|c|}{ Post test } & \multirow[t]{2}{*}{ 't' Value } \\
\hline & & Mean & STD & Mean & STD & \\
\hline 1 & $\begin{array}{c}\text { Experimental } \\
\text { Group }\end{array}$ & 7.25 & 2.8 & 8.2 & 3.0 & $\mathrm{t}=2.0^{*}$ \\
\hline \multirow[t]{2}{*}{2} & $\begin{array}{l}\text { Control } \\
\text { Group }\end{array}$ & 7.9 & 2.9 & 7.7 & 2.76 & $T=0.661$ \\
\hline & & \multicolumn{5}{|c|}{$\mathrm{T}=2.16^{*}$} \\
\hline
\end{tabular}

Table 2 Comparison of Pretest and Post test Concept Map scores

\begin{tabular}{|c|c|c|c|c|c|c|c|}
\hline \multirow[t]{2}{*}{ S.No } & \multirow{2}{*}{$\begin{array}{l}\text { Part of the } \\
\text { concept map }\end{array}$} & \multicolumn{2}{|c|}{ Pretest } & \multicolumn{2}{|c|}{ Post test } & \multirow[t]{2}{*}{ 't' value } & \multirow[t]{2}{*}{ Significance } \\
\hline & & Mean & STD & Mean & STD & & \\
\hline 1 & Preposition & 45.87 & 6.4 & 60 & 17.5 & 2.603 & $p=0.035$ \\
\hline 2 & Hierarchy & 5.1 & 0.7 & 5.9 & 1.1 & 1.0 & $p=0.351$ \\
\hline 3 & Examples & 2 & 3.0 & 5.4 & 3.7 & 2.077 & $p=0.076$ \\
\hline 4 & Cross links & 11.62 & 6.7 & 22.5 & 12.6 & 2.391 & $p=0.048$ \\
\hline 5 & Total Scores & 192.25 & 68.9 & 319.75 & 143.6 & 2.506 & $p=0.041$ \\
\hline
\end{tabular}

which depicted the effectiveness of the training programme $(t=2.16, p=0.05)$. A significant difference was identified between the pretest and posttest critical thinking scores of experimental group at 0.05 level $(t=2.0)$. It again showed that the critical thinking scores improved following the training programme. (Fig 3 )

The concept maps prepared by the fourth year nursing students for the given case scenario in Midwifery were evaluated using the scoring key. The mean pretest and post test scores of concept maps for prepositions were (45.8, $6.0)$, for hierarchy $(5.1,5.8)$, for example $(2,5.4)$, for cross links $(11.6,22.5)$ and for the total scores, it was 192.25 and
319.75 respectively. The comparison of pretest and post test concept map scores showed significant difference in all the aspects of concept map except for the hierarchy. (Table 1) The total post test concept map scores showed a significant improvement from the pretest concept map scoresat $p=0.041$ level $(t=2.506)$. $($ Fig 4$)$

The different components of concept maps had shown significant difference except the hierarchy level. The Hierarchy level indicates the linear thinking which is not an area of critical thinking, whereas the identification of meaningful prepositions and cross links had shown a significant difference which denotes non linear thinking in 
students, indicative of significant development of critical thinking.

The students felt that the concept map was very interesting and they motivated them to think and reason out better. Few of the students found it difficult initially and able to draw the maps later. Few of them felt that it was difficult to change the nursing process format now as they were used to the traditional way of making nursing care plans for the past three years. 'If it has been practiced from the first, it would have been the best method to follow' they said. They expressed that their thinking process has had a significant change by doing the concept maps. They told that they were able to see the relationships between the concepts better and they could identify newer relationships which they had not known or thought before.

\section{Conclusion:}

Though there was a significant improvement in the critical thinking scores among the experimental group, the overall scores of the experimental and the control group were found to be very poor. The reason for the poor CT scores

\section{References:}

1. Daly WM. The development of an alternative method in the assessment of critical thinking as an outcome of nursing education. J Adv Nurs. 2001; 36(1): 120-30.

2. Clayton LH. Concept M apping: An Effective, Active Teaching-Learning Method Nursing Education Perspectives. Jul/Aug 2006: 27(4); p 197 204

3. Giddens J Concept mapping as a group learning activity in graduate nursing education. Journal of nursing education. 2006 Jan : 45(1) ; P $45-46$

4. Vacek J. Using a Conceptual Approach with Concept Mapping to Promote Critical Thinking. Journal of Nursing Education. 2009 Jan 1; 48(1): 45-8. In: ProQuest M edical Library [database on the Internet]

5. Lindesay M C and Irvine BA. Can concept mapping be used to promote meaningful learning in nurse education? Journal of Advanced Nursing. 1995: 21; p1175-79

6. Rusbult C. Critical thinking in education. Updated on July 2006. Cited on 7.4.2008. Available from http://www.asa3.org/ASA/education /think/critical.html

7. UNM College of Nursing. Critical Thinking in Nursing. 2006. Retrieved from: http://hsc.unm.edu/consg/critical/measurement.shtml

8. University College of the Cariboo, Critical Thinking: To think like a nurse, Available from : www.cariboo.bc.ca/nursing/faculty/ heaslip/nrsct.htm

9. Billings DM. Argument mapping. The journal of continuing education in nursing. 2008 Jun : 39(6); p 246-247

10. NovakJD \& Canas AJ. The theory underlying Concept $M$ aps and how to construct and use them, Technical Report IHM C CmapTools 2006-01 Rev )1-2008, Florida Institute for Human and Machine Cognition, 2008, available at: http://cmap.ihmc.us/publications/Research Paper/ TheoryUnderlyingConceptM aps.pdf

11. Clayton LH. Concept Mapping: An Effective, Active Teaching-Learning Method Nursing Education Perspectives. Jul/Aug 2006: 27(4); p 197- was analyzed. While collecting the feedback from the students, they expressed that the standard and the language used in the assessment tool was very high and they found it difficult to understand in the first time and needed to read it again which was time consuming and tiring. There is a great need to develop a standardized assessment tool to assess the critical thinking skills which will be suited for the nursing community.

There is a lacunae related to the awareness of the nurse educators on the use of concept mapping in nursing and nursing process. It demands further research to establish concept mapping as one of the innovative teaching strategy which promotes critical thinking skills among the nurses.

The continual use of concept mapping in the clinical setup will help in improving the CT skills. The nurse educators can be trained to use and teach concept mapping to plan the nursing care by the students in the clinical areas. In due course, this will improve the quality of nursing care for the patients.

\section{4}

12. Wheeler LA and Collins SK. The influence of concept mapping on critical thinking in Baccalaureate nursing students. Journal of Professional Nursing. 2003 Nov-Dec; 19(6): 339-346

13. Cañas, A.J., Leake, D.B., \& Wilson, D.C. (1999). M anaging, mapping and manipulating conceptual knowledge. AAAl Workshop Technical Report WS-99-10: Exploring the synergies of knowledge management $\&$ case-based reasoning, AAAI Press, M enlo CA

14. Steele F. How Concept M aps can be scored or assessed? Visual wiki. June 2007.Giddens J Concept mapping as a group learning activity in graduate nursing education. Journal of nursing education. 2006 Jan : $45(1) ; P 45-46$

15. Protzman KM and Raval V concept mapping - a learning tool for the information systems audit profession. Information systems Control Journal. Vol. 3, 2004. www.isaca.org

16. Wilgis $\mathrm{M}$ and M cConnell J. Concept mapping: An educational strategy to improve graduate nurses critical thinking skills during a hospital orientation programme. The journal of continuing education in Nursing. 2008 March:39(3); p119-26.

17. Abel WM and Freeze M. Evaluation of concept mapping in an associate degree nursing program. Journal of nursing education. 2006 Sep: 45(9); p356-365

18. Simone CO Conceição, Linda D Taylor. Using a constructivist approach with Online Concept Maps: Relationship between Theory AND Nursing Education. Nursing Education Perspectives. 2007 Sep 1; 28(5): 268-75. In: ProQuest M edical Library [database on the Internet]

19. Daley, Barbara J. University of Wisconsin- Milwaukee. Using concept maps with adult students in higher education. 2004. http://209.85.173.132/ search?q=cache:M NzQGDN4VRw):cmc.ihmc us/ papers/cmc2004-05 